International Review of Research in Open and Distributed Learning Volume 18, Number 7

November - 2017

\title{
Special Report on the Role of Open Educational Resources in Supporting the Sustainable Development Goal 4: Quality Education Challenges and Opportunities
}

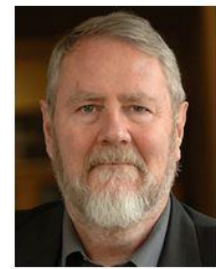

Dr Rory McGreal

UNESCO/COL/ICDE Chair in OER

Athabasca University

\section{Quality Education: Role/Contribution of OER}

Open Educational Resources (OER) and their offspring, Massive Open Online Courses (MOOCs), are becoming important factors in achieving the Sustainable Development Goal 4: Quality Education (SDG4). This was recognised early on by UNESCO in 2004 when they first coined the term "Open Educational Resources" and in 2012 with the OER Paris Declaration. UNESCO is continuing its support of OER with the $2^{\text {nd }}$ OER Summit in September 2017. There is recognition that OER and MOOCs, while not being the solution to the world's educational crises, will play an important, if not essential, role. The OER movement is less than 15 years old and is growing rapidly as more and more nations and institutions adopt the view that publicly-funded research and educational content belongs to the people and should therefore be open and accessible to them. Canada can play an important role in supporting SDG4 by increasing its support for OER and open education in general, both in Canada and abroad.

It is reasonable to argue that OER can greatly benefit developing countries, even more so than those that are considered developed. As such, they can play an important transformative role in supporting the SDG4 goal. OER can be used to increase access to learning for those living in unfavourable circumstances, and can also be used to address issues of cost, quality, and equity. They are free of licensing restrictions that inhibit quality improvements and because they are openly available, OER can facilitate both internal and external collaborations among instructors and institutions, both locally and internationally, while ensuring equitable access to knowledge and learning. OER are presently being actively used in all sectors of education including literacy, vocational, and adult education, as well as with immigrants and refugees (with prior learning assessment and recognition). OER can be instrumental in improving the quality of 
education through open curriculum development. And, most importantly, OER are digital; the world economy is digital and students must learn how to work (and play) in digital environments.

Because OER can be reproduced at virtually no cost, they can be effectively used to reach vast numbers of learners, while supporting quality enhancements. As well, since they can be reused, revised, remixed, redistributed, and retained, OER can be adapted to different learning environments (Wiley, 2014). It was UNESCO that first used the term open educational resources, defining them as "teaching, learning or research materials that are in the public domain or released with an intellectual property license that allows for free use, adaptation, and distribution" (UNESCO, 2002, par. 2). The UNESCO Paris Declaration of 2012 followed, supporting OER for development and recommending that educational materials developed with public funds be made available under open licenses (UNESCO, 2012). Additionally, because OER are open, they can be translated into different languages and localised to meet the needs of different countries, regions, institutions, and learners (Butcher, Kanwar, \& Uvalic-Trubic, 2015).

OER, as content, are free of cost to learners and teachers. However, there are other costs that must be taken into account, including the salaries and time of the OER creators/adapters/assemblers. These costs can be significantly reduced by sharing OER with other institutions. For example, an institution, rather than creating its own course material, can choose to make use of OER that have been created by others, thus saving the cost of content creation; however, there still may be costs for searching/finding, assembling, and adapting the content. In addition, an appropriate technological infrastructure needs to be in place with access to adequate bandwidth and wifi, as well as trained support staff. (Please note that these costs are the same when using commercial content.) Furthermore, the cost of commercial textbooks is becoming a greater problem as the prices are all too often increasing beyond the ability of students to pay for them. As a result, there has been rapid growth in the number of learners internationally, who cannot afford the high cost of textbooks. The advantage of OER is that they are cost-free and can be adapted freely. The ability to adapt and modify content is an important advantage, especially when targeting specific populations such as those with disabilities or special needs.

\section{Indigenous Knowledge}

OER can also be used to preserve and distribute Indigenous knowledge, which is being supported now in many countries. OER can be used to support the "participatory principle" that is common in many Indigenous communities, as well as preserving and distributing Indigenous knowledge that has traditionally been open. Indigenous knowledge is seen as belonging to the community as a whole and like OER, it can be continually enhanced and expressed in many forms such as in stories, dance, songs, and through the wisdom of elders. Sharing is conducted through personal interactions among the community/kinship or religious groups (Bertini, 2010).

\section{Maskwacis First Nation Cultural College}

As a Canadian example, in Alberta, the Chair has worked with this college to introduce them to OER. They received funding from the Ministry of Advanced Education for the development of Indigenous content 
aimed at driving "stronger Indigenous perspectives in Alberta post-secondary learning." The project was designed to support the need for Indigenous students to learn in new technological environments and become digital citizens, while maintaining their Indigenous perspectives. They have implemented several courses in OER and even translated the Creative Commons licences into the Cree language.

\section{Indo-Educa}

This is a community-based OER project building a repository for Indigenous content in both Portuguese and different Indigenous languages. The organisers believed that OER was a concept "fundamentally in sync" with the Indigenous way of knowing. The aim was also to preserve traditional knowledge, while linking Indigenous communities with the wider society. Indigenous university students were enlisted to prepare relevant and appropriate OER for use in schools. The OER preserve and open access to more than 200 traditional stories, rituals, beliefs, and other cultural artefacts (Rossini \& Castro, 2016).

\section{AgShare II}

This is a collaborative project in OER of three universities: Haramaya (Ethiopia), Makerere (Uganda), and Mekelle (Ethiopia). Its aim was to investigate the forms of Agricultural Indigenous Knowledge used by different groups of farmers for managing soil fertility and preparation, pest control, and diseases, weed control, planting, harvesting and storage of Indigenous root crops and animals (AgShare II, 2015,). This research project sponsored by the Bill and Melinda Gates Foundation has determined good strategies for documenting and disseminating Indigenous knowledge as OER, which is contributing to both sustainable food security efforts and educational for all.

Considered very important by many are the affordances available with OER that support innovation in teaching and learning. The training of faculty in the use of educational technology is a major task. Faculty must not only master the technology, but also be skilled in its pedagogical uses to improve learning outcomes. OER, because of the flexibility and openness, can enable the best teaching practices and increase student achievement levels both for knowledge and skills. The open licences used by OER, unlike commercial content, allow users to localise content to meet the special conditions of learners, teachers, institutions, and nations. For example, OER can be designed to meet the accreditation requirements of schools and agencies, or they can be translated to local languages or adapted to respect the exigencies of a particular culture. They can also be used to support active learning by students. OER can be manipulated and altered to support this and other constructivist approaches to learning; students can work with instructors in creating more effective learning environments (Butcher \& Hoosen, 2012).

OER can be used to create alternate or complementary pathways to education. It is estimated that there will be a need for more than 80 million places for additional students internationally by 2025 (Daniel, 2012). OER can be used to create additional places using access to credentials as, for example, the case of the $\mathrm{OERu}$, which is a consortium of plus 30 institutions on five continents, creating OER pathways to degrees from credible public universities (Mackintosh, McGreal, \& Taylor, 2011).

MOOCs grew out of the open education movement and, as such, represent an important part of the OER landscape. Yuan and Powell (2013) have described how MOOCs developed out of the OER, open education, open source, and open access movements, although there are also commercially licensed 
versions of MOOCs now in operation, such as Udacity and Coursera. Weller (2014) has described MOOCs (at least the non-commercial ones) "as part of a continuum" that has proceeded from open source computing, to open access, OER, and open education.

Commercial etextbooks and other content come with Digital Rights Management (DRM) otherwise known as Technological Protection Measures (TPM) or colloquially as "digital locks." These "locks" on materials restrict students from making effective use of the content. They cannot copy, paste, highlight, print out, change devices, etc. In addition, there are legal restrictions that prevent users from breaking locks or making use of the content as they would like. For example, they are legally prohibited from showing their etextbook content to anyone else. The publishers own all the data created, and they control how the textbook is used. Because of these restrictions, it is essential for educators to use OER, which can be used freely without locks or legal restrictions.

\section{Canada: An International Leader in OER}

Canada has important areas of expertise in OER at the post-secondary level. Although there is no federal government strategy specifically supporting OER or other forms of open education, there has been activity at the provincial level in Western Canada, and more recently in Ontario with the creation of eCampus Ontario. For the most part, OER development and open initiatives in Canada have focused at the level of individual institutions and on access and availability issues as opposed to practice and policy and/or initiatives to encourage openness (McGreal, Anderson, \& Conrad, 2015).

Canada is unique in the world in that it is the only country whose national government has no authority in education; in Canada, education is exclusively a provincial responsibility. In large and complex countries with diverse educational institutions, especially in a Confederation such as Canada, where each province has total autonomy in education, it is difficult to be aware of the many varied practices and policies that are emerging. While other countries can develop national policies, it is only possible in Canada to develop trans-Canadian provincial partnerships in education, but these partnerships operate without national government involvement.

Nevertheless, there are several national open access initiatives, including the federal government's Open Data pilot project, which enables access to content that can be used to support OER development. In addition, the Tri-Council funding agencies-Canadian Institutes of Health Research (CIHR), the Natural Sciences and Engineering Research Council of Canada (NSERC), and the Social Sciences and Humanities Research Council (SSHRC)-have all agreed on a Tri-Agency Open Access Policy, supporting open access publishing of all federally-funded research. While, this federal policy focuses on research publications, many of these, when used for teaching, can be considered to be OER. There is confusion between OER and open access, along with the concept of openness in general; there is a large grey area between open access and OER, in addition to openness. Even so, the federal government policies support the principle that all publicly-funded content should be openly accessible and reusable.

Nationally, the Council of Ministers of Education, Canada (CMEC) has supported the UNESCO OER 
Paris Declaration, reaffirming "their commitment to open access to knowledge and education and to the need to adapt teaching and learning practices to the new realities of the information age" (Council of Ministers of Education Canada, 2012, p.15). The Vancouver-based Commonwealth of Learning was a copartner with UNESCO in initiating the first UNESCO conference in 2012; and they are continuing this partnership in supporting the 2017 UNESCO summit in Slovenia.

Canada is perceived as a world leader in OER, primarily because of the initiatives in British Columbia and Alberta. B.C. was the first province to initiate an OER project where BCcampus has created and populated a repository of more than 150 open textbooks. Alberta followed with a $\$ 2$ million project to support the creation, assembly, and adaptation of OER. Regionally, the three Western provinces of British Columbia, Alberta, and Saskatchewan have signed a Memorandum of Understanding agreeing to cooperate on the development of common OER (Memorandum of Understanding, 2014). Alberta, Campus Manitoba and eCampus Ontario have partnered with BCcampus in using the Open Textbook repository. In 2016, eCampus Ontario sponsored an OER Request for Proposals available to Ontario post-secondary institutions.

Canadian leadership has been recognised by the Open Education Consortium: Alberta hosted the 2015 international conference in Banff Athabasca University received an Award of Excellence for the OER Knowledge Cloud, a repository of more than 1600 scholarly articles and reports related to OER; the UNESCO/COL/ICDE Chair at Athabasca University received a Lifetime Achievement Award; and BCcampus has also received an Open Education Consortium Award of Excellence in Education.

The reality in Canada is that, although there are significant initiatives in OER at the post-secondary level, there is little if any activity in the primary and secondary levels (K12) other than ad hoc implementations by individual teachers. (Unlike the USA, where there are now more than 25 states supporting OER in K12 schools, and South Africa with Siyavula's open textbooks for primary and secondary schools).

The creation and use of OER benefits from the development and use of Creative Commons licences, which provide the legal framework to share these resources. Creative Commons (CC) Canada, an affiliate of the larger international body, is an organization born of the global open education movement. The author of this paper and UNESCO Chair is the board member of CC Canada, and Canadian-born Ryan Merkley is now the CEO of Creative Commons worldwide. Most recently, in May 2017, the CC international Summit meeting was held in Toronto.

OER universitas (OERu) offers free online university courses in collaboration with Canadian partners so that learners can gain formal credentials from the partner institutions. As has been previously noted, OERu is a consortium of more than 30 institutions and several organizations on five continents. It is dedicated to widening access and reducing the cost of post-secondary education for learners internationally by providing OER pathways to achieve formal and recognized credentials (McGreal, Mackintosh, \& Taylor, 2013). There are seven members of the OERu located in Canada: three universities (Athabasca, Thompson Rivers, and Kwantlen Polytechnic); one community college (Portage College in Alberta); and three organizations (BCcampus, eCampus Alberta, and Contact North in Ontario). Two Canadians sit on the OERu Board of Directors: Dr. David Porter, CEO of eCampus Ontario, and Prof. Rory McGreal, UNESCO/COL/ICDE Chair in OER. 
Following a recommendation by the Organisation Internationale de la Francophonie, whose conference was hosted in February 2013 in Moncton, NB, there has been renewed interest in Québec in the promotion of des ressources éducatives libres (REL). The Ministère de l'Éducation, du Loisir et du Sport du Québec is financing the website BRER (banques de ressources éducatives en réseau), which hosts French language OER as well as other content. Thot Cursus is another Québec organization that has implemented a repository that includes OER. These are rather limited initiatives, in comparison with the Western Canadian initiatives and with France, which is strongly committed to REL. Sophie Touzé, who serves as an expert in Digital Education and Pedagogy for the French Ministry of Higher Education and Research, has been elected president of the international Open Education Consortium.

It is not well known that MOOCs are Canadian in origin. The name dates to an experimental course led by George Siemens at the University of Manitoba and Stephen Downes at the National Research Council in 2008 (Tamburri, 2014). They taught a MOOC titled, Connectivism and Connective Knowledge (Downes \& Siemens, 2008) with more than 2,200 learners online.

The Canada-based Commonwealth of Learning (COL) is charged with promoting open education throughout the 53 countries of the Commonwealth. They have been supporting OER and delivering MOOCs to Commonwealth citizens since 2013. In 2017, in collaboration with Athabasca University, they are delivering a MOOC entitled, Introduction to Technology Enabled Learning, which is accessible globally. Several of Canada's larger universities have been delivering MOOCs as part of the Coursera or EdX consortia based in the USA. As an example, The University of Alberta delivered one of the first such MOOCs in Canada on Dinosaur Paleobiology in 2013.

The International Development Research Centre continues to be very active in supporting OER research. They are the donor (C $\$ 2.8$ million) for The Researching Open Educational Resources for Development (ROER4D) project, which is a South-South research network on OER and development. This network, with participants in South America, Asia, and Africa is charged with analysing and producing knowledge on the impact of OER in higher education. A previous project in Asia has led to major OER initiatives in several countries (International Development Research Centre [IDRC], 2017)

Open Access (OA) to scholarly research is related to OER. Open Access supports open licensing for research rather than education. Nevertheless, OA can be used as OER, if the open content is used in a teaching/learning context. The three Canadian research funding agencies-CIHR, NSERC, and SSHRChave agreed on a policy supporting open access in scholarly publications. OA initiatives also include support for OA Journals. The SSHRC and UNESCO supported International Review of Research in Open and Distributed Learning (IRRODL) was one of the first open journals worldwide. There is also support for open university presses such as AUPress at Athabasca University and limited open titles from the University of Ottawa Press and others. Universities are also promoting openness through the use of Creative Commons (CC) licences.

To move forward as international leaders, Canadian OER supporters must continue to increase awareness of OER among learners, teachers, administrators, and most importantly, among provincial education officials who are in a position to support open policies including those responsible for the CMEC. Specifically, provinces should be encouraged to build on the Tri-Council decision to support open access 
for research and extend it to OER in both higher education and in the schools. The experience of Alberta shows that students, concerned about the increasing price of textbooks, can have a significant impact on government policies regarding OER. Leadership is enjoyed by those who are actually implementing OER initiatives. The implementation of open education in Canada remains in its early stages. However, the growing interest in MOOCs, the recent OER initiatives, and the inter-provincial partnership MOU in Western Canada, could well be harbingers of future cooperative and/or collaborative developments in Canada, placing it as a leading nation on a fast track to national and international collaborations, policy, and standards in open education.

\section{OER: Opportunities and Challenges}

Perhaps the most important opportunity for OER is in the global free exchange of knowledge. OER render this knowledge not only accessible but also reusable by learners and teachers in a variety of formats; anyone can access information on the Web, but if it is restrictively licensed, it cannot be downloaded or reused, whereas OER does allow this. In addition (as previously noted), OER are very much "in sync" with the "participatory principle" noted in diverse Indigenous communities and so can provide Indigenous organisations with an opportunity to support the distribution and preservation of their cultures and Indigenous knowledge (Bertini, 2010). OER have also made possible a move towards South-South exchanges, whereas previously knowledge flowed uni-directionally from the North to the South. For example, lusophone learners in Brazil are accessing Portuguese language OER created by the African Virtual University (Diallo, 2011).

Any implementation of OER becomes an opportunity that presents challenges. OER can save time and money, but as has been noted above, the implementation does not come without costs both one-time and recurring. One-time costs include those of searching, transferring, adapting, assembling, etc., while the recurring costs are for the infrastructure and updating. Note, that there are similar costs when implementing commercial content. Many teachers and learners still do not understand the difference between freely accessible content on the internet and OER, believing that all web resources are OER (Chen \& Panda, 2013).

However, most available OER are in English. This can be seen as both an opportunity and a challenge as the English language is widespread as a first or second language in most countries, counting hundreds of millions of speakers, but it is still not understood by the vast majority of the world's people. Another major challenge for OER advocates is to overcome what has been seen as a unilingual and one-directional flow of knowledge and resources from the global North to the South (Glennie, Harley, Burcher, \& van Wyk, 2012), often referred to as "cultural imperialism," based on an unequal distribution of power.

A most serious challenge for the global South, and in underserved remote regions in the global North is the lack of infrastructure. This includes not only available devices but also access to high bandwidth either by wire or wireless. Nevertheless, more than $90 \%$ of the world's population is within range of effective wireless signals, which raises opportunities for learning using mobile device (M-learning). The demand for a mobile learning can be used to convince governments of the importance of providing an adequate, 
reasonably priced infrastructure to elevate the educational level of citizens.

The increasing volume of OER that are becoming available represents an opportunity for teachers and learners everywhere. On the other hand, this increasing volume has created a serious challenge in the effort that is often required to find and evaluate relevant OER (Chen \& Panda). However, this is becoming less of a barrier in the first year of higher education, as more robust and capable search engines and OER repositories are becoming available for searching out content in the major subject areas. In less popular subjects and in the upper levels of university, finding relevant OER still remains problematic.

OER can also be used to raise the quality of education, not only of the teaching content but also of the teaching itself by supporting the transformation of the educator's learning environment. Nevertheless,

quality issues have been raised regarding the use of OER. Criticisms include not just subject matter quality, but quality in relation to the local environment, culture, and pedagogy. However, unlike commercial content that must remain static and untouched, OER can be localised and customised to the specific environment and to different approaches to learning. They can also be formatted for delivery in a variety of ways including print form, when needed. In India, the National Knowledge Commission (NKC) has recognized that OER can be used to address the poor quality of teachers, poor infrastructure, poor libraries, and poor educational resources. They recommend that OER can be very effective in reducing these problems and improving the quality of education while increasing accessibility (Dutta, 2016)

There are an increasing number of OER and MOOC initiatives being implemented internationally. To date, most projects have been in North America and Europe; however, important exceptions include Siyavula and the African Virtual University (AVU) in South Africa, the Indian NKC OER initiative, and several universities in Asia. There is research on several of these initiatives, their impact on the demand for OER, and on their reuse. Lessons can be learned from these and also from research on activities in the more developed countries (Das, 2011; Dhanarajan \& Porter 2013; Dutta, 2016).

\section{MOOCs (Massive Open Online Courses)}

There are huge educational benefits becoming available through MOOCs. These are not limited to significant cost savings, which can be substantial, because they can also provide worldwide access to highquality learning content with at least vicarious interactions with experienced instructors. This combined with anytime, anywhere learning, make MOOCs, combined with OER, a valuable and significant factor in meeting the United Nations and UNESCO's educational goal. While providing access to learning for large numbers of learners, MOOCs have become instrumental in the transformation by institutions to more technologically enhanced learning, improving the quality of both online and blended learning. On the other hand, MOOCs have been criticised for the quality of their pedagogy, relying on traditional video lecture formats; their low completion rates; and a failure to deliver on inclusive and equitable quality education (Darco, Rosewell, \& Kear, 2016)

MOOCs represent a major opportunity for meeting the Quality Education goal. However, they also present serious challenges. MOOCs cannot be seen as a solution for all (like classroom-based teaching, 
which is not for all and has its own challenges). MOOCs are being used by many institutions solely as a marketing tool. Moreover, to date, MOOCs are mostly being accessed by those with higher levels of education rather than the masses of learners who lack access to traditional education (Rohs \& Ganz, 2015). It is argued that MOOCs are simply extending the digital divide by expanding inequalities of opportunity. In addition, other barriers can be insurmountable for many learners. These include information overload, lack of local language support, and access to well-trained teaching professionals. Educators must find new strategies for addressing the needs of these non-traditional learners. Nevertheless, MOOCs can be used to improve educational quality while massifying the educational market. Haber (2014) cautions that just because they are not a cure-all does not mean that MOOCs are not important in promoting quality education - despite their limitations.

The future of MOOCs will depend on approaches taken to accreditation. Students not only want to learn but also want their learning recognized officially. The OERu is attempting to remedy this with their OER courses and testing by the participating universities (for a fee) for students who want a credential. Several MOOCs now offer certificates while others offer badges. Automated testing and prior learning assessment will play a key role in supporting credentialing as MOOCs become more popular.

MOOCs have the potential to open up education to many more students at substantially lower costs. Scholarships can be awarded to students who monitor other students in MOOCs. The world economy is digital and students can learn to help each other online and become proficient digital citizens. MOOCs are capable of being used to reach large numbers of teachers anywhere at any time and are in fact benefiting from this now. For example, The Commonwealth of Learning and Athabasca University are delivering Technology Enabled Learning training via a MOOC to large numbers of learners, many of whom are in the least developed countries or on small island states.

\section{UNESCO/COL Chair in OER and Awareness Training}

The full potential of OER and their MOOC offspring can be realised with executive commitments and the approval of strong open education policies, along with the implementation of appropriate technologies (Miao, Mishra, \& McGreal, 2016). These measures should be combined with training for knowledge about OER and the skills to effectively use them. These include expanding awareness of OER and MOOCs; the integration of OER into institutional administrative frameworks; and developing and applying sustainable OER business models, including faculty incentives (Cox \& Trotter, 2016).

The role of the UNESCO/COL/ICDE Chair in OER is to continue lobbying for OER initiatives and policies among the relevant constituencies (School Boards, Higher Educational Institutions, Ministries of Education and Advance Education, faculty, students, etc.) in Canada and internationally, particularly in the global South, in order to expand participation and extend access. The Chair must lead by example by collaborating on OER projects with other Canadian and international educators and researchers, as well as those in his home institution. He has a role also in advising administrators and government officials in how best to implement OER initiatives, including quality assurance and issues of privacy and ethics 
(Ferguson, Scanlon, \& Harris, 2016, p.21). The creation of templates, standards, and guidelines for OER implementations and use are also important activities that are being undertaken.

Success builds on success. The Chair in OER has been instrumental in supporting BC's initial leap into OER; was heavily involved with students in the lobbying of the Alberta government to support OER, resulting in a \$2 million grant; and was named co-Chair of the Alberta OER initiative. His efforts have had some (if limited) influence in Ontario where he has advised Ministry and eCampus Ontario officials on OER. Internationally, universities in Malaysia, Pakistan, India, the Philippines, South Africa, Uruguay, Bahrain, and other countries, have all benefitted from OER consultations with the Chair, resulting in many responding with significant OER initiatives. The role of the Chair, then is to support OER implementations wherever possible.

\section{OER: Advancing Sustainable Development Goal 4?}

\section{Ensure Inclusive and Equitable Quality Education and Promote Lifelong Learning Opportunities for All}

As I have represented above, OER can be a significant aid in ensuring inclusive and equitable quality education and can promote lifelong learning opportunities for all. OER, by their very nature as freely available and usable learning resources, can be considered important, if not essential, for supporting the expressed goals in all areas of education. From pre-kindergarten to lifelong learning, including technical and vocational training, OER can have significant impact.

Governments can better support free K12 education financially because the OER are available at no cost. They can be taken "as is" or modified and they can be made available to all. This includes all levels from early childhood to secondary school. Affordable education for vocational and technical education as well as university is also made more affordable with OER. MOOCs with their ability to serve large numbers of users can be used to increase the number of youth and adults with relevant skills. Gender disparities can be diminished when both men and women have equal access to the free content. People with disabilities will benefit, because the OER can be adapted and reformatted to meet their individual needs. And, OER fit very well with the community-sharing culture of many Indigenous communities.

One of the biggest boosts to literacy is the open availability of OER. They not only assist in promoting literacy education, they actually can serve as an incentive. With the world's knowledge freely available and re-usable, this provides a reason for people to become literate and numerate, not to mention technology literate.

OER can be used to help ensure that all learners acquire the knowledge and skills needed to promote sustainable development, including, among others, through education for sustainable development and sustainable lifestyles, human rights, gender equality, promotion of a culture of peace and non-violence, global citizenship and appreciation of cultural diversity, and of culture's contribution to sustainable development. OER can be child, disability, and gender sensitive, and provide safe, nonviolent, inclusive, 
and effective learning environments for all, including diverse Indigenous communities. And if not, OER can be altered and or modified to be so.

\section{Acknowledgments}

This paper was made possible by a grant from the Canadian Commission for UNESCO.
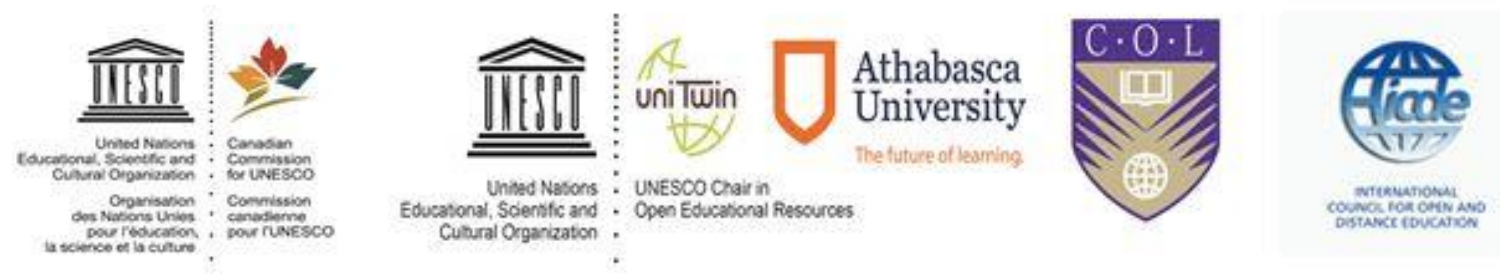

\section{References}

AgShare II. (2015). Agshare II OER. Retrieved from http://oerafrica.org/agshare/

Bertini, G. (2010, November 16). What can the Open Educational Resources movement learn from Indigenous Knowledge Systems? [Blog post]. Retrieved from https://gfbertini.wordpress.com/2010/11/16/what-can-the-open-educational-resourcesmovement-learn-from-indigenous-knowledge-systems/

Butcher, N., Kanwar, A., \& Uvalic-Trumbic, S. (2015). A basic guide to open educational resources (OER) [eBook]. Retrieved from http://www.unesco.org/new/en/communication-andinformation/resources/publications-and-communication-materials/publications/full-list/abasic-guide-to-open-educational-resources-oer/

Butcher, N., \& Hoosen, S. (2012). Exploring the business case for Open Educational Resources. Retrieved from http://www.col.org/resources/publications/Pages/detail.aspx?PID=421

Chen, Q., \& Panda, S. (2013). Needs for and utilisation of OER in distance education: A Chinese survey. Education Media Internationl, 50 (2). Retrieved from http://www.tandfonline.com/doi/abs/10.1080/09523987.2013.795324

Council of Ministers of Education Canada. (2012, July 6). Ministers of Education mark a milestone in education cooperation [Blog post]. Retrieved from http://www.cmec.ca/278/PressReleases/Press-Releases-Detail/Ministers-of-Education-Mark-a-Milestone-in-EducationCooperation-.html?id article $=508$ 
Cox, G., \& Trotter, H. (2016). Institutional culture and OER policy: How structure, culture, and agency mediate OER policy potential in South African universities. IRRODL, 17(5). Retrieved from http://www.irrodl.org/index.php/irrodl/article/view/2523

Daniel, J. (2012, February 1). Invest in clicks not bricks5th eLEX Conference. Hamdan Bin-Mohamed eUniversity: Commonwealth of Learning [PDF]. Retrieved from http://oasis.col.org/bitstream/handle/11599/1096/2012 Daniel Clicks Bricks Transcript.pdf? sequence $=1 \&$ is Allowed $=\mathrm{y}$

Darco, J., Rosewell, J., \& Kear, K. (2016, August 12). Quality frameworks for MOOCs. In M. Jemni, Kinshuk, \& M. K. Khribi (Eds.), Open education from OER to MOOCs. Springer. Retrieved from http://link.springer.com/chapter/10.1007\%2F978-3-662-52925-6 14

Das, A. K. (2011). Emergence of open educational resources (OER) in India and its impact on lifelong learning. Library Hi Tech News. Retrieved from http://www.emeraldinsight.com/doi/abs/10.1108/07419051111163848

Dhanarajan, G., \& Porter, D. (Eds.). (2013). Open educational resources: An Asian perspective: Commonwealth of Learning. Retrieved from http://oasis.col.org/handle/11599/23

Diallo, B. (2011, May 4). Emerging open courseware projects: AVU Teacher Education Program [SlideShare presentation]. Retrieved from https://www.slideshare.net/OCWConsortium/emerging-open-courseware-projects-bakarydiallo-avu

Dutta, I. (2016). Open Educational Resources (OER): Opportunities and challenges for Indian higher education. Turkish Journal of Distance Education, 17(2). doi:http://dx.doi.org/10.17718/tojde.34669

Downes, S., \& Siemens, G. (2008). Connectivism and connective knowledge [Blog post]. The Daily Archives. Retrieved from http://connect.downes.ca/archive/08/09 15 thedaily.htm

Ferguson, R., Scanlon, E., \& Harris, L. (2016). Developing a strategic approach to MOOCs. Journal of Interactive Media in Education.(1). Retrieved from http://doi.org/10.5334/jime.439

Glennie, J., Harley, K., Butcher, N., \& van Wyk, T. (2012). Open educational resources and change in higher education: Reflections from practice [eBook]. Retrieved from http://oasis.col.org/handle/11599/80

Government of Canada. (2016, December 21). Tri-agency open access policy on publications [Blog post]. Retrieved from http://www.science.gc.ca/eic/site/063.nsf/eng/h_F6765465.html?OpenDocument

Haber, J. (2014). MOOCs. Cambridge, MA: MIT Press. 
International Development Research Centre (IDRC). (2017). Open educational resources. Retrieved from https://www.idrc.ca/en/search/gss/open\%20educational\%2oresources

Mackintosh, W., McGreal, R., \& Taylor, J. (2011). Open education resources (OER) for assessment and credit for students project: Towards a logic model and plan for action [PDF]. Retrieved from http://hdl.handle.net/2149/3039

McGreal, R., Anderson, T., \& Conrad, D. (2015). Open educational resources in Canada 2015. International Review of Research in Open and Distributed Learning, 16(5). Retrieved from http://www.irrodl.org/index.php/irrodl/article/view/2404

McGreal, R., Mackintosh, W., \& Taylor, J. (2013). Open educational resources university: An assessment and credit for students initiative In R. McGreal, W. Kinutha, \& S. Marshall (Eds.), Open educational resources: Innovation research and practice. Vancouver: Commonwealth of Learning. Retrieved from http://www.col.org/PublicationDocuments/pub PS OER$\underline{\text { IRP web.pdf }}$

Memorandum of Understanding Open Educational Resources. (2014, March 13). Retrieved from http://www.gov.sk.ca/adx/aspx/adxGetMedia.aspx?mediaId=f3d342c4-ab61-44a4-9f9671ceb7810a5d\&PN=Shared

Miao, F., Mishra, S., \& McGreal, R. (2016). Open educational resources: Policy, costs and transformation [eBook]. Retrieved from http://unesdoc.unesco.org/images/0024/002443/244365e.pdf

Rohs, M., \& Ganz, M. (2015). MOOCs and the claim for education for all: A disillusion by empirical data. . International Review of Research in Open and Distributed Learning, 16(6). Retrieved from http://www.irrodl.org/index.php/irrodl/article/view/2033

Rossini, C., \& Castro, O. (2016). The state of open educational resources in Brazil: Policies and realities. In F. Miao, S. Mishra \& R. McGreal (Eds.), Open educational resources: Policy, costs and transformation. Vancouver: Commonwealth of Learning/UNESCO. Retrieved from http://unesdoc.unesco.org/images/o024/002443/244365e.pdf

Tamburri, R. (2014, February 12). An interview with Canadian MOOC pioneer George Siemens. University Affairs. Retrieved from http://www.universityaffairs.ca/features/feature-article/aninterview-with-canadian-mooc-pioneer-george-siemens/

UNESCO. (2002). Forum on the Impact of Open Courseware for Higher Education in Developing Countries: Final Report. Retrieved from http://unesdoc.unesco.org/images/0012/001285/128515e.pdf

UNESCO. (2012). UNESCO Paris Declaration on Open Educational Resources [PDF]. Retrieved from http://www.unesco.org/new/fileadmin/MULTIMEDIA/HQ/CI/CI/pdf/Events/Paris\%20OER\%2 oDeclaration 01.pdf 
Weller, M. (2014). The battle for open: How openness won and why it doesn't feel like victory. London: Ubiquity Press. DOI: https://doi.org/10.5334/bam

Wiley, D. (2014, March 5). The access compromise and the 5th R [Blog post]. Retrieved from https://opencontent.org/blog/archives/3221

Yuan, L., \& Powell, S. (2013, March). MOOCs and open education: Implications for higher education [Blog post]. Retrieved from http://publications.cetis.org.uk/2013/667

\section{Athabasca} University

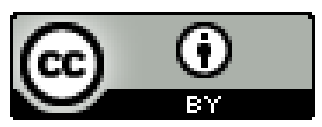

